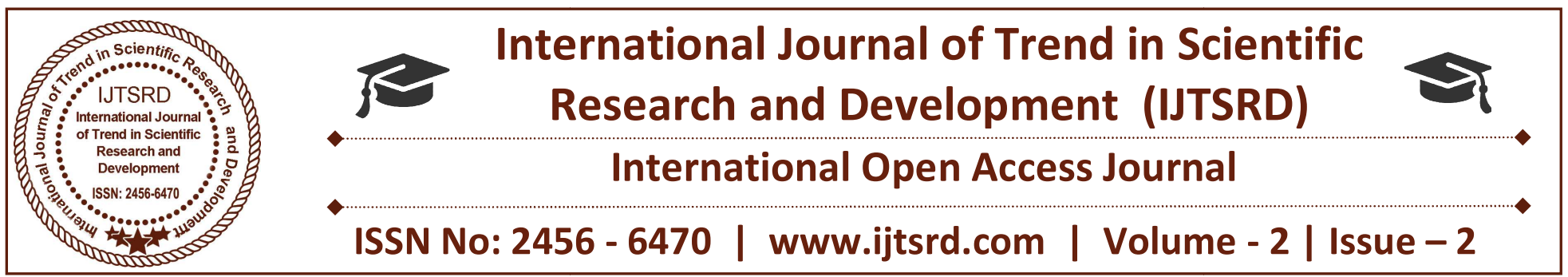

\title{
Anxiety on Body Image among Females Students of Pakistan (A Ternary Model of Body Image Exasperation Appraisal)
}

\author{
Hamid Mahmood \\ Lecturer, Department of \\ Management Sciences \\ University of Okara, Pakistan
}

\author{
Adnan Shaukat \\ Ms Scholar, Department of \\ Management Sciences, Comsats \\ Institute of Information \\ Technology Sahiwal, Pakistan
}

\author{
Usman Akram \\ Student, Department of \\ Management Sciences, \\ University of Okara, Pakistan
}

\section{ABSTRACT}

In present study tripartite influence model was examined with large sample of university females' students (ages 18-29). This model is amalgamation of core source of influence i.e. peer, parents and media which contribute to development of body dissatisfaction\& image perception. Quantitative data was analyzed by using SPSS 19 software and was also analyzed through Amos version 21 and confirmatory factor analysis conducted to verify the validity of adaptive instruments. In current study social comparison and internalization of thin body ideal significantly develop body dissatisfaction and image perception among university female students and also mediate the relationship of sociocultural factor (peer, parents, and media) and body dissatisfaction and image perception. Present study yet offering replication and extension of pervious work with social comparison and internalization of thin body ideal with Muslim ethnicity and provide support for further testing of tripartite model.

Keywords: Body dissatisfaction, Image perception, Social comparison, Internalization of thin body ideal

\section{INTRODUCTION}

\section{Background:}

The perception of a person is developed by the players who are interacting with him in the community he lives i.e. social players. Therefore, individual perception is reality that shape reactive behaviors which are influence by social players [1].On the other hand, humongous growth of media during last decade has also develop individual's perception materialistically[2]. Now culture is a driving force that influences the females how they perceive about their physical appearance but in current era female are not confident about their body and in their own natural physic \& skin. Mass media is continually causing insecurities in their feministic physic [3].

Females are seductively and objectively represented in media of Pakistan, about $65 \%$ of heavy media viewers from which $71 \%$ audiences which watch digital advertisement campaigns have strong believed that media does not follow the cultural and social norms. $76 \%$ study respondents believe that advertisements using mixed cultural approach and portray of females is not as per societal values. Females' bodies are used to catch charms for the products only, even though have not direct utility of these products. Media expression passively advert the dressing style and communication expressions [4].

Media exposures significantly moderate the behaviors and damage psychological health of young people; among them females are the objects which getting direct impact on their physical appearance. Media authorities and investors are interested in making their financial pockets deeper by brainwashing average females mind through females' portray materialistically in media and the focus is on physical 
shapes, body parts and transparent dressing[5]. Mass media's important right arm i.e. cable TV is spreading the Indian culture in our society which negatively affect Islamic culture in Pakistan [6].

People trade their health over body image dissatisfaction in younger age and females feel anxiety about their body shape from 15 to 34 years of age and peers influence is also robotic force to adopt dietary behavior [7]. Pakistan is a Muslim country with $97 \%$ Muslims citizen and is world's second most Muslim populous country having Islamic values (Pakistan-Language, Religion, Culture, Customs and Etiquette). With respect to materialism of female in Muslim society which is not acceptable because females should have dressed as per Islamic values and traditions.

But some of the families have already adopted western culture due to media influence. Being a member of global village that is controlled by mass media, media in Pakistan has been truly emerged from last decade, in relation to this a study was conduct to measure the body image dissatisfaction of universities students that revealed $58.8 \%$ female students are even pressurized by their family members to perceive their body image adversely view that their family opinion pressurized perceive body image, $61.4 \%$ female students believe that their body image perception is influence by their peers who spend greater time on media [8].

Consumer culture adversely altar the materialistic ideal beauty and perfect physical appearance of young females and mass media is spreading the image of ultra-thinness physic that cause dissatisfaction in young females [9]. Life stage from school to universities increasingly dependence on media perception that cause unhealthy psychological \& physical behavior [10]. Body dissatisfaction is individual passive thinking about their physic, body parts, body appearance and weight \& size [11].

From the past few decade social players consider female desirable, eye catching and appealing when she looks thin and this societal requirement causes dissatisfaction within their own body and weight [12]. Higher the body dissatisfaction and higher will be the internalization of thin body ideal which mediate the relationship of several psychological and sociocultural variables [13]. Sociocultural factors relation mediates with body dissatisfaction by social comparison [14].
The present study has a specific aim to investigate the tripartite model to dig out the relationship of sociocultural factors, body dissatisfaction which mediate by social comparison and internalization of thin body ideal. Second aim is to elaborate the pressure which caused by the media on young universities female about their body image perception.

\subsection{Statement of the Problem:}

Female roles in society portrayed through mass media are imbalance and not fair to acceptable in Muslim society. Females are not only presented nonsense, dependent human but also her real life feelings and behaviors are neglected consciously, females are used to spread a seductive and glamorous image. It is harsh for females to follow the fantasy roles in their real life facilities and environment settings. The morning shows which are designed and telecast or online broad casted generally for female audiences does not portray conventional role. For attraction seeking purpose females are used as an object in advertisements campaigns which have no direct utility of product. In the bitter wounding of females psychological and emotional feelings, not only one player of society (Media) is responsible, but also social players Peers, parents. Media message creator agencies and commercial entities are equally blame holders [15].

Females' representation in movies which is adverting to cultural and social norms. In which she is over glamorized and a worse portray far away from realities of life promotes unhealthful behavior, damage societal traits. Sixteen countries around the globe banned 3500 elements of media which negatively represent females and pressurized them to adopt a worse societal role. Pakistan is a paradise for these items and huge quantity selling market [16]. Media escape their real image from advertisement and media events which portray females in Islamic mood with no human worth at all not in world as well as in Pakistan. Female's worth has been fully escaped and is present in imaginative way. This portray is effecting the dignity of females which is given by Quran, Sunna, and Islamic society [17].

Time has been radically changing from previous years, females have become career oriented and media is viable molder of this mind set. Images seen in dramas and television of young females are leaving greater influence on their minds, the conscious force behind is to adopt the behavior as portrayed in media through specific media young female celebrities [18]. 
Every national and multinational advertisement campaigns use females to sell their product and got attractiveness even using in those products campaign which not direct utility for females [19].

\subsection{Research Objective:}

1) To determine the strength of relationship between social factor, social comparison, internalized the appearance media ideal body and body dissatisfaction.

2) To evaluate the peer and parents pressure on female psychic to feel dissatisfaction about their body image.

3) To evaluate the influence of media on female body image perception.

4) To evaluate the social factor's influence on female perception to go for social comparison and internalization of thin body ideal.

\subsection{Research Questions:}

1) Is there a relationship between social influence factors, social comparison, internalization of appearance ideal body and Body dissatisfaction?

2) Do females perceive greater pressure from peer and parent to feel dissatisfaction their body image

3) Are females are objectified in media and perceive greater pressure from media feel dissatisfaction their natural physic?

5) Do peer, parents, and media force females to go for social comparison and internalized the media ideal body image?

\section{LITERATURE REVIEW}

\section{Body dissatisfaction:}

The study with body mass index results explained that female body dissatisfaction boosts up with the increase in age while remain the stable for males with increase in age [20]. Study revealed that women dieting habit caused by public image and taken overall results explore that some females are self-focus dieters having negative perception about their bodies and positive towards body dissatisfaction.[21] Study explained that female having high scores of body dissatisfaction socio-cultural ideal image and internalization of thinness and less satisfied with their physical appearance[22].
Female are the most affect behavior of body dissatisfaction and have strong negative feeling about image perception therefore men also affected clearly by body dissatisfaction[23]. Study results founded that without video intervention girls having affected from thin models and cause body dissatisfaction and lesser self-reverence. While after exposure of thin models video intervention decrease the impact of effect exposure [24].

\section{Parental influence:}

Study revealed that parental influence cause huge amount of variation in body dissatisfaction [25]. Study conceded that intimate inspiration the body dissatisfaction over and done with the path way of social comparison. Parental care for young females reduce the body image dissatisfaction their relationship mediates by internalization of thin ideal body[26]. Study founded that sister was also a social cultural agent that forces young girls to focus on thin physic. Study investigated that parents cause pressure on young females through thinness discussion and encourage through activities to reduce eating [27]. Study explained that young adult females have greater perception for dissatisfaction with their body in comparison to their moms[28].

\section{Peer influence}

Every day meeting with peers affect the body satisfaction of young females negatively, peers' influence emerges the behavior towards internalization of thin body ideal [29]. Peers have transforms the psychic of young females towards internalized thin body image. Peers have a direct influence on body dissatisfaction of adolescent young girls. Study explored that preadolescent school girls have perception to be thin and feel dissatisfied about their bodies that perception due to peer's influence on mental health [30]. Peers' perception and adoption of thinness image cause little desire in girls to become thin.

\section{Media influence:}

Media consumption force women to think about thin body and leads towards disturbance in young female psychic about body satisfaction negatively[31]. Media effects on female to feel bad about their bodies but relationship in mediate by Social comparison.TV exposures partially influence the student's behavior such as effect on partner attraction but no significant effect on clothing style and eating attitude [32]. 
Premature girls spend time over mass media feel pressure about their body image. Media has transformed the female psychic to feel dissatified bodies and try to become thin.

\section{Internalization of Thin body ideal:}

Self-clarity of female influence the body image perception and IATI mediate the relationship [33]. Internalization of thin body ideal promoted and measured risk factor which caused body dissatisfaction among young college females. Socitel players have sound impact on the body image satisfaction of females [34]. Time consumption over media demostrate the physic of internalization of thin ideal body image that ultimately cause body dissatisfaction. Internalization of thin body ideal leading predictor that effect the body satisfaction image of young school females, globalization main cause for this effect on young consumer psychic and most of culture facing this problem [35].

\section{Tripartite Influence Model:}

Socio-cultural factors have triggered the body dissatisfaction but their relationship mediates by social comparison. The study explicated that peer's chit chat and criticism indirectly influence the body dissatisfaction amongst youngsters and lassies and relationship mediate internalization of appearance ideal factor[36]. Media influence play major role in body dissatisfaction of college females but peer and parental predictors haven't significant effect on body dissatisfaction. Socio cultural significant predictor of image disturbance and results were same as previous studies proved [37].

\section{Social Comparison}

Internalization of the thin ideal clues female juveniles to communally equate themselves to others. [38] originate that associated to male's females were supplementary prospective to communally equate themselves when assessing their own physique and had lesser body esteem as divergent to males. Fascinatingly, body dissatisfaction did not differ between males and females. What did fluctuate was that guys have a tendency to sight their frames as thinner than the ideal, however women their physiques as grander than the perfect. [39] accompanied a correspondence Study which enquired women to ascertain what corporeal eccentricities they first discerned when beholding at a successions of snaps.

\section{Social Comparison theory:}

[40] was flip the theory of social comparison in which he explains that personalities would equate themselves with others and evaluate the similarities and differences within both personalities. But in upward comparison an individual compare themselves with people to whom they perceive grander that source downheartedness, anxiety, anger and selfworseness. Social comparison source that people equate themselves with others (family, peers, colleagues) and imagine that images that seen by others helpful to accomplish their goals.

\section{Attachment theory:}

Attachment theory is one of the most famous speculative standpoint theory which stimulus the research on close relationships, companionship and melancholy. At the prompt juncture the negative experience contributes significantly to the anomalous progress and behavior ailment in next prompt of lifespan. [41] contended that eminence of affection significantly influencing succeeding development, containing neurotic expansion.

\section{Systematic theory:}

Some canvassers[41] have faith in that the study of humanoid progress being with the atmosphere of the adolescent, Pubescent and atmosphere has significant stimulus on the progression of progress. Bronfenbrenner bio ecological archetypal of humanoid progression emphases on the setting of progress which transpire in the magnetism of personages and cluster within and athwart setting. This model focuses on the issues of creature, course, situation and time sights the atmosphere nested methods that include palmtop system (instant milieu and interactions), ecosystem (interrelationships among Microsystems tie to the individual), and macro-system includes culture, norms, radians, values. So these structures are unified and cause sway on human progression.

\section{Psychoanalytic view:}

Psycho-analytic e.g. and neo-psycho-analytic theory alleged that offspring primary life relationship experience inaugurate the succeeding social and persona progress later in lifespan. Conferring to Freud, ample of the grownup temperament is regulate beforehand pubertal and be contingent upon the efficacious transition from prior progress phases [42]. 
In the psychosomatic model, anorexia and bulimia nervosa as healthy as chubbiness are escorted by adverse physique spitting image and anxiousin take arrays or starving provisions. These syndromes obvious with specific domestic communiqué configurations and procedures of skirmish perseverance [43].

\section{Media theory:}

Media properties are broadly sight seen and have been the subject of wide spread investigation. "The media are demarcated as conduits for diffusing communications to specific spectators in a tactic to fascinate and ailment their devotion for echo acquaintance [44]." These investigation appearances at three customs of media that convey memoranda: goggle-box, periodicals and the Internet. Scholars clinch that goggle-box and periodicals contemporary superlative picture of attractiveness and commercialize philosophies around physique size and prettiness.

\section{Objectification Theory:}

The developed objectification philosophy through their research efforts focused on sex and gender and the sociocultural implications of being15either male or female; most notably, the sexual objectification of women. Historically, objectification theory focused solely on women's body image concerns. However, it has also recently become a popular framework for understanding men's body image concerns.

\section{Theories/ Model of body dissatisfaction:}

The inclination in topical years has been headed for considerate the decisive aspects intricate in the expansion and preservation of physique spitting image fracas [45]. [46] offer criticism of numerous philosophies and mockups of body disorder. Imperative to reminder, these academics incline to use the rapports philosophy and archetypal interchangeably. Numerous causes interrelated to physique spitting image have added unusual courtesy in the nonfiction.

\section{Integrative Mockups of Body Image Dissatisfaction}

Although there are numerous philosophies on the expansion of physique spitting image, a complete examination publicized that scarce trainings use mockups that assimilate the numerous philosophies.
First, urbanized an integrative archetypal that prerequisites expenitential taxing. These archetypal synopses two stimuli: (1) ancient, progressive stimuli that silhouette physique spitting image insolences such as behavior features, somatic aspects and socialization and (2) proximal stimuli that regulate how a separable practices her/his body on an everyday base. In spirit, the archetypal advises that these stimuli on body image consequence in dysphonic, which stimulates folks to absorb in actions and stratagems marked to decrease suffering.

\section{Dimension of Body Image Dissatisfaction}

In the historical binary spans, there has been a progress of experiential enquiry on body frustration [46]. Not with standing augmented examination and a progress of valuations to quantity features of body image, due to extent issues it is difficult to determine incidence of females annoyed with their bodies, who has written expansively on body image, claims that while investigators show praiseworthy exertions to ignoble their work on a conjectural basis, they incline to oversee important dimension subjects in the area of body image. He offers numerous endorsements for investigators and clinicians, from precisely cataloguing the body image breadth under study to data scrutiny.

\section{Contributions of the current study:}

The present study makes three contributions. First, previous studies of body dissatisfaction \& image perception focused mainly on western society females. Only a few studies focused on Asian females. This study will expand knowledge about body dissatisfaction \& image perception to cover adolescent girls with Muslim ethnicity. Second, previous studies identified that western, Asian and Jewish identity females having greater pressure from media parents and peers, but Jewish females having greater pressure from their father. Third, previous studies investigating western adolescent girls' gender role and identity perceptions were mainly conducted in different ethnicity in western society and Japanese's context those are modern and non-Muslim population. In the present study, the survey was conducted with less develop and non-modern cities of Pakistan to measure the perception of body image dissatisfaction. 


\section{THEORATICAL FRAMEWORK}

(Berg, 2002; Keery, 2004; Yamamiya, 2008; Lawler, 2011; Rogders, 2011; Hardit, 2012; Tylka, 2012)

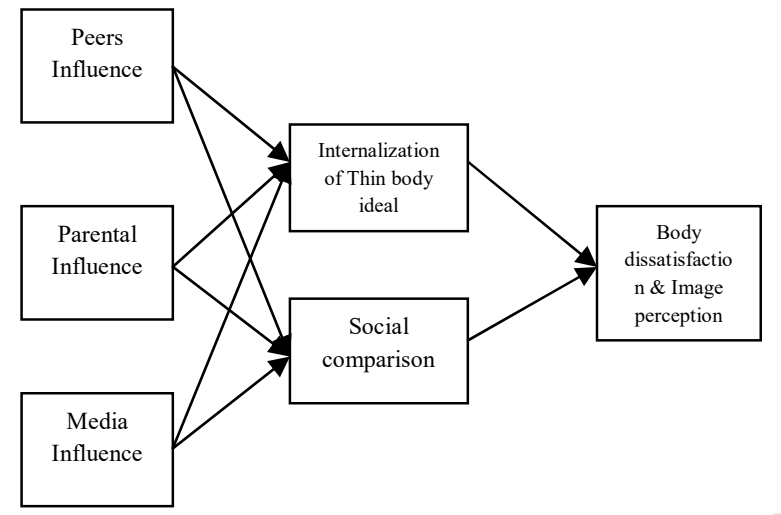

\section{Research Hypotheses:}

H1: There is a positive affiliation between peer influence and internalization of thin body ideal.

$\mathrm{H} 2$ : Thee is a positive affiliation between peer influence and social comparison.

H3: There is a positive affiliation between Parental influence and internalization of thin body ideal.

H4: There is a positive affiliation between Parental influence and social comparison

H5: There is a positive affiliation between media influence and internalization of body ideal.

H6: There is a positive affiliation between media influence and social comparison.

H7: There is a positive affiliation between internalization of body ideal and body dissatisfaction \& body image perception.

H8: There is a positive affiliation between social comparison and body dissatisfaction \& body image perception.

\section{RESEARCH METHODOLOGY}

\section{Research Philosophy}

The present dissertation philosophy is positivism (basic research), subsequently the realism is objective and individuals can effortlessly recognize this authenticity. Consequently, signs can be exploited to pronounce and elucidate this objective study [47]. In contemporary study variables are used to pronounce and enlighten the objective reality.

\section{Research Approach}

The contemporary approach of dissertation is deductive. Meanwhile the opinions are coherent from universal evidences. Which moreover are acknowledged or assumed to be identified in progress: in the direction of a more convinced and unambiguous supposition.

\section{Nature of Research}

The nature of research of this particular dissertation is explanatory in nature, as it does not only anticipate not only designating statistics and physiognomies about population, but moderately enlightening when, how and why such singularities seemed or transpired.

The data were collected in classes such as: Marketing, psychology, business education classes.

\section{Procedures for Data Collection}

The process for data gathering was in obedience with guidelines for the protecting the human rights of respondents. Once the etiquette for the research had been permitted by the stratum universities, the scholar communicated faculty who furnished their authorization to gather data in their tutorial and organized a data assortment time.

The scholar attained at the tutorial at the approved upon time, familiarized the study to the apprentices, clarified that the answers are entirely unspecified, and disseminated the survey. While the scholar lingered in the lecture theater to reply any queries that might ascend, a box or large wrapper positioned away from the scholar was made accessible to the apprentices in whom they were to place their finalized surveys. The students were well-versed that they would "lumber" the surveys in the wrapper upon accomplishment. Once the final student had left the classroom, the scholar recovered the packet.

\section{Sample}

One objective of the contemporary research was to scrutinize body image in a usual somewhat than a scientific taster. This was imperative since the massive mainstream of investigation in the expanse of body image progress has absorbed on a treatment-in the hunt for an inhabitant that varies from common inhabitants in standings of close of psychopathology [48]. Likewise, it varieties an essential support to the nonfiction because a sympathetic of the progress of optimistic body image is a significant fragment of complete self-reverence in a common population. 
Present research was accompanied in outsized Sahiwal region universities in Pakistan. Data were unruffled from 559 campus students who agreed from amongst a total of 2600 enrolled in business administration, literature, social sciences courses in universities of Sahiwal region, Pakistan. This signifies a $20 \%$ proportion of partaking. All contestants were among the eternities of 18 and 31 (intermediate age of 25). Amongst the 566 inspections that were poised, 34 participants signposted a therapeutic ailment that necessitatesunusualfare (anemia, stomach disease and pregnancy). They were disqualified from the research.

\section{Quantitative approach:}

In this study we use the quantitative approach because data is large and for this approach large sample is also required. The imperative cause to usage the reckonable approach is that it eliminates the biasness. This investigation also sieves out the peripheral influences and if it is glowing premeditated it can afford dispassionate and the authentic consequences [49].

\section{Research Design:}

This is the research gathered data via inspection with a feedback form. Survey research practice will be used to pucker the statistics from sample of people since survey has an improvement of gathering the evidence quickly, it is not only less expensive but also efficiency and accuracy is achieved by the means of gathering the information from the population.

So it is easy to find out the significant results in Body dissatisfaction. We use the questionnaire for the collection of data so it will be

\section{Data collection Method:}

This study will be used the Stratified sampling so it will be the probability sampling technique. Because the culture, lifestyle, peers' interaction, social class varies within each university selected for study purposes. On such bases stratum will developed and select equal respondents from each stratum.

\section{Sample unit:}

Sample unit are the University female students of Sahiwal and Okara district. Over partial of the women age 18-25 deliberate would choose to be run over by a lorry than to be fat, and two-thirds would choose to be nasty or senseless rather than overweight. Females' university students are the most effect perception to think about their physical appearance negatively because facing social comparison and pressure from media and peers.

\section{Sample Size:}

Universities selected as a population has more than 6500 students in multiple disciplines from which 40\% representatives' are females. An online sampling adequacy calculator is used to standardize the sample for current research work. 20\% sample of small population will be enough to standardize the results. The sample size will be 600 and 150 each sample size from 4 universities of Sahiwal and Okara.

\subsection{Population:}

The target population of this study will be considering the Female students of four universities of Sahiwal and Okara which is 2600 female students from four universities. Better to use the explanatory research [50].

\section{Instrumentation:}

Surveys were reproduced on 8.5 -by 11 -inch rag and managed throughout a systematic 90 minutes lecturer at under the direction of the passage tutor and the scholar. Partakers who offered for partaking in the study were guaranteed of the concealment of replies and the intentional environment of their partaking. Contributors were permitted to work on Studies pending the questionnaires were finalized. No scholar essential additional than 25 minutes to thorough the survey. The investigator poised all finished surveys in envelop place away from scholar for ethicality of research. The primarily page of the survey consisted of demographic questions interrelated to age, height and height, educational back ground, parental educational level, desire weight and height that will respondent actually want.

\section{SATAQ-3:}

The procedures that were accomplished by contestants comprised the Eating Attitudes Test (EAT-26), the Socio cultural Attitudes Just before Appearance Scale - 3 (SATAQ-3), the Physical Appearance Comparison Scale (PACS), the Physical Appearance State and Trait Anxiety Scale, an inclusive body dissatisfaction Visual Analogue Scales, and the Zung Self-Rating Depression Scale. As a final point, a demographics questionnaire asked contestants nearby 
their tallness, weightiness, age, sprint, and year in seminary, and this form was directed at the end of the study in directive to lower the risk of persuading replies to images. Metaphors and psychometric possessions of the procedures are providing underneath.

\section{Data Analysis Techniques:}

The questionnaire data were entered directly into an SPSS data file. Appropriate transformations were applied to those items that obligatory inverse coding. AMOS 21 version was used to conduct for Structural Equation Modeling. Total scores were subtracted for each scale. The Confirmatory factor analysis with Varimax rotation was functional for plummeting the integer of items from the Variables, and Cronbach's alpha was used for ascertaining the reliabilities. Structural Equational Modeling (SME) technique was used for measuring the causal relationships, Present study follow the assumption without direct relationship measure so results of study just concealed indirect relationship. Correlation analysis was used for measuring association between all variables. Convergent and discriminant validity was used for measuring the construct validity of present. The Kaiser Meyer Olkin (KMO) test was used for measuring adequacy of present study sample.

\section{FINDINGS}

\begin{tabular}{|l|l|l|}
\hline \multicolumn{3}{|l|}{ Kaiser-Meyer-Olkin and Bartlett's test } \\
\hline $\begin{array}{l}\text { Kaiser-Meyer-Olkin measure of } \\
\text { sampling adequacy }\end{array}$ & 0.923 \\
\hline $\begin{array}{l}\text { Bartlett's test of } \\
\text { sphericity }\end{array}$ & $\begin{array}{l}\text { Approx. } \\
\text { Chi-square }\end{array}$ & $\begin{array}{l}19342 . \\
592\end{array}$ \\
\cline { 2 - 3 } & Df & 593 \\
\cline { 2 - 3 } & Sig. & 0.001 \\
\hline
\end{tabular}

The Kaiser Meyer Olkin (KMO) test is used for the measure the sample adequacy test which show that whether your data is suitable for the factor analysis or not in this model the KMO value is above from .6 and Bartlett's test of sphericity is significant (value should be .05 or smaller) so in this table sample adequacy is 0.923 and Bartlett's test of sphericity is significant 0.001 .

Another process to show the significant relationship between different variables is Bartlett's test of sphericity. The purposes of Bartlett's test of sphericity evaluate the test of null hypotheses that the variables in the population correlation matrix are uncorrelated. So if the $\mathrm{p}$ value is significant (means less than .005) than it is enough to reject the hypothesis. It is concluded precede a factor analysis for the data.

\begin{tabular}{|l|l|l|l|l|l|l|}
\hline Predictors & $\begin{array}{l}\text { Parental } \\
\text { influence }\end{array}$ & $\begin{array}{l}\text { Peer } \\
\text { influence }\end{array}$ & $\begin{array}{l}\text { Media } \\
\text { influence }\end{array}$ & $\begin{array}{l}\text { Social } \\
\text { comparison }\end{array}$ & $\begin{array}{l}\text { Internalization } \\
\text { of appearance } \\
\text { body ideal }\end{array}$ & $\begin{array}{l}\text { Body } \\
\text { dissatisfaction }\end{array}$ \\
\hline Parental influence & $\mathbf{1}$ & & & & & \\
\hline Peer influence & 0.341 & $\mathbf{1}$ & & & & \\
\hline Media influence & 0.561 & 0.511 & $\mathbf{1}$ & & & \\
\hline Social comparison & 0.439 & 0.493 & 0.671 & $\mathbf{1}$ & $\mathbf{1}$ & \\
\hline $\begin{array}{l}\text { Internalization of } \\
\text { appearance body } \\
\text { ideal }\end{array}$ & 0.623 & 0.534 & 0.562 & 0.691 & $\mathbf{1}$ & $\mathbf{1}$ \\
\hline $\begin{array}{l}\text { Body } \\
\text { dissatisfaction }\end{array}$ & 0.546 & 0.619 & 0.573 & 0.451 & 0.678 & \\
\hline
\end{tabular}

Correlation analysis was conducted to measure the strength of association between variables. Correlation matrix elaborates the significant relation between social influence variables, mediating variables internalization of appearance body ideal, social comparison and body dissatisfaction. Majority of variables associations are $>0.5$ which shows the strong association. 
International Journal of Trend in Scientific Research and Development (IJTSRD) ISSN: 2456-6470

\section{Convergent Validity and Construct Reliability:}

Cronbach's Alphas \& Composite Reliability Coefficient for Latent Variables

\begin{tabular}{|l|l|l|l|l|l|}
\hline Constructs & $\begin{array}{l}\text { No. of AVE } \\
\text { Items }\end{array}$ & $\begin{array}{l}\text { Cronbach's } \\
\text { Alpha }(\alpha)\end{array}$ & $\begin{array}{l}\text { Composite } \\
\text { Reliability } \\
\text { Coefficient (CRC) }\end{array}$ & Communality \\
\hline Parent Influence & $10^{*} / 7 * *$ & 0.5189 & 0.805 & $0.843^{*} / 0.834^{* *}$ & 0.5189 \\
\hline Peer Influence & $8^{*} / 7^{* *}$ & 0.5825 & 0.817 & $0.866^{*} / 0.878^{* *}$ & 0.5825 \\
\hline $\begin{array}{l}\text { Media Influence } \\
8 * / 7 * *\end{array}$ & 0.5326 & 0.812 & $0.856^{*} / 0.879^{* *}$ & 0.5326 \\
\hline $\begin{array}{l}\text { Social } \\
\text { comparison }\end{array}$ & $10^{*} / 6^{* *}$ & 0.5144 & 0.928 & $0.891^{*} / 0.895^{* *}$ & 0.5144 \\
\hline $\begin{array}{l}\text { Internalization of } \\
\text { thin body Ideal }\end{array}$ & $9 * / 6^{* *}$ & 0.5645 & 0.818 & $0.844^{*} / 0.856^{* *}$ & 0.5645 \\
\hline $\begin{array}{l}\text { Body } \\
\text { Dissatisfaction }\end{array}$ & $11^{*} / 7 * *$ & 0.5454 & 0.787 & 7 & 0.5454 \\
\hline
\end{tabular}

Hence three items from parent influence, one item from peer and media influence, 4 items from social comparison, three items from internalization of thin ideal body and four items from body dissatisfaction burnout scales were removed because of their low factor loading, the purpose is to obtain the better model fit for each latent construct. The outcome of before and after confirmatory factor analysis demonstration that all circumstances the Cronbach's alpha catalogues and composite reliability coefficients momentously outstrip the least possible mentioned flat of .70 , signifying that these capacity measures have in elevation internal consistency.

The AVE value and communality value is $>0.5$ and composite reliability and Cronbach's alpha value $>0.7$ therefore all the necessities for convergent and construct validity is achieve.

\section{Discriminant Validity:}

\begin{tabular}{|l|l|l|l|l|l|l|}
\hline Predictors & $\begin{array}{l}\text { Parental } \\
\text { influence }\end{array}$ & $\begin{array}{l}\text { Peer } \\
\text { influence }\end{array}$ & $\begin{array}{l}\text { Media } \\
\text { influence }\end{array}$ & $\begin{array}{l}\text { Social } \\
\text { comparison }\end{array}$ & $\begin{array}{l}\text { Internalization } \\
\text { of appearance } \\
\text { body ideal }\end{array}$ & $\begin{array}{l}\text { Body } \\
\text { dissatisfaction }\end{array}$ \\
\hline Parental influence & $\mathbf{0 . 7 5 7 6}$ & & & & & \\
\hline Peer influence & 0.2261 & $\mathbf{0 . 7 5 2 1}$ & & & & \\
\hline Media influence & 0.3249 & 0.2116 & $\mathbf{0 . 7 5 0 1}$ & & & \\
\hline Social comparison & 0.2666 & 0.3423 & 0.2423 & $\mathbf{0 . 7 6 7 3}$ & & \\
\hline $\begin{array}{l}\text { Internalization of } \\
\text { appearance body } \\
\text { ideal }\end{array}$ & 0.2094 & 0.4356 & 0.2184 & 0.2786 & $\mathbf{0 . 7 5 4 9}$ & \\
\hline Body dissatisfaction & 0.3036 & 0.2496 & 0.2341 & 0.3134 & 0.4652 & $\mathbf{0 . 7 2 3 1}$ \\
\hline
\end{tabular}

According to [52] enlighten that Discriminant validity investigation shows how greatly variance in the indicators that are able to enlighten variance in the variable. Discriminant validity value explore from the square root of AVE value. The diagonal values (in bold) are the square root of AVE while other values are the correlation among the particular variables. In this case, the Discriminant validity is determined when a transverse value bold is privileged than the value in its row and column. Hence the diagonal values (in bold) are greater than the values in the rows 
and columns so the assumption of Discriminant validity is achieved.

\section{Measurement model}

Since the Family, Peer and Media Scale is a scale developed specifically for this study, its factor structure was unknown. Therefore, before using its subscales as indicators for the family, peer and media latent variables, confirmatory factor scrutiny was conducted on the substances. A three factor structure for the items was hypothesized a priori and its fit was found to be adequate, $\mathrm{c} 2(24)=54.62, \mathrm{P}<.05$, $\mathrm{RMSEA}=.086, \mathrm{CFI}=.95, \mathrm{AGFI}=.87$.

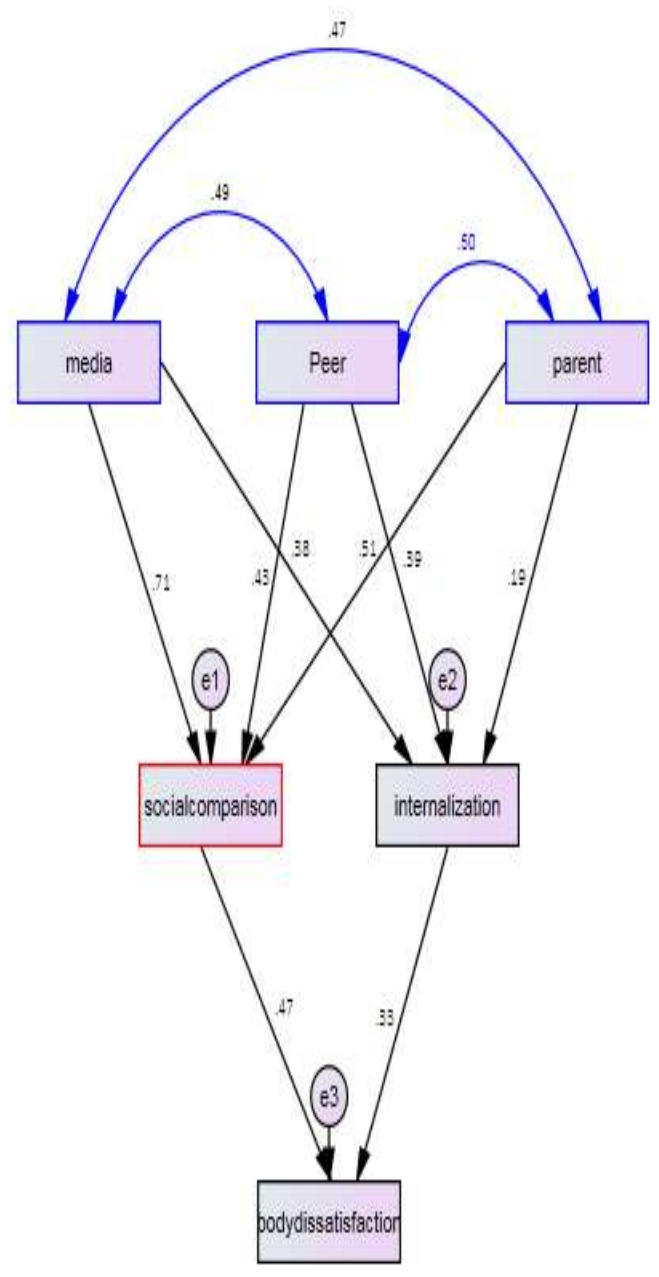

Structural Equational Model:

SEM is statistical process to reconnoiter the fundamental link amongst the variables in fundamental model. The SEM include all the dormant and regulator construct and theoretically driven affiliation among them, to gauge the significance of hypotheses paths and the illuminating power of the model by subtracting the R2 values for each endogenous construct. The $\mathrm{R} 2$ refers to the proportion of discrepancy of the endogenous variable that is elucidated by the set of exogenous construct [53].

\section{Measurement Model:}

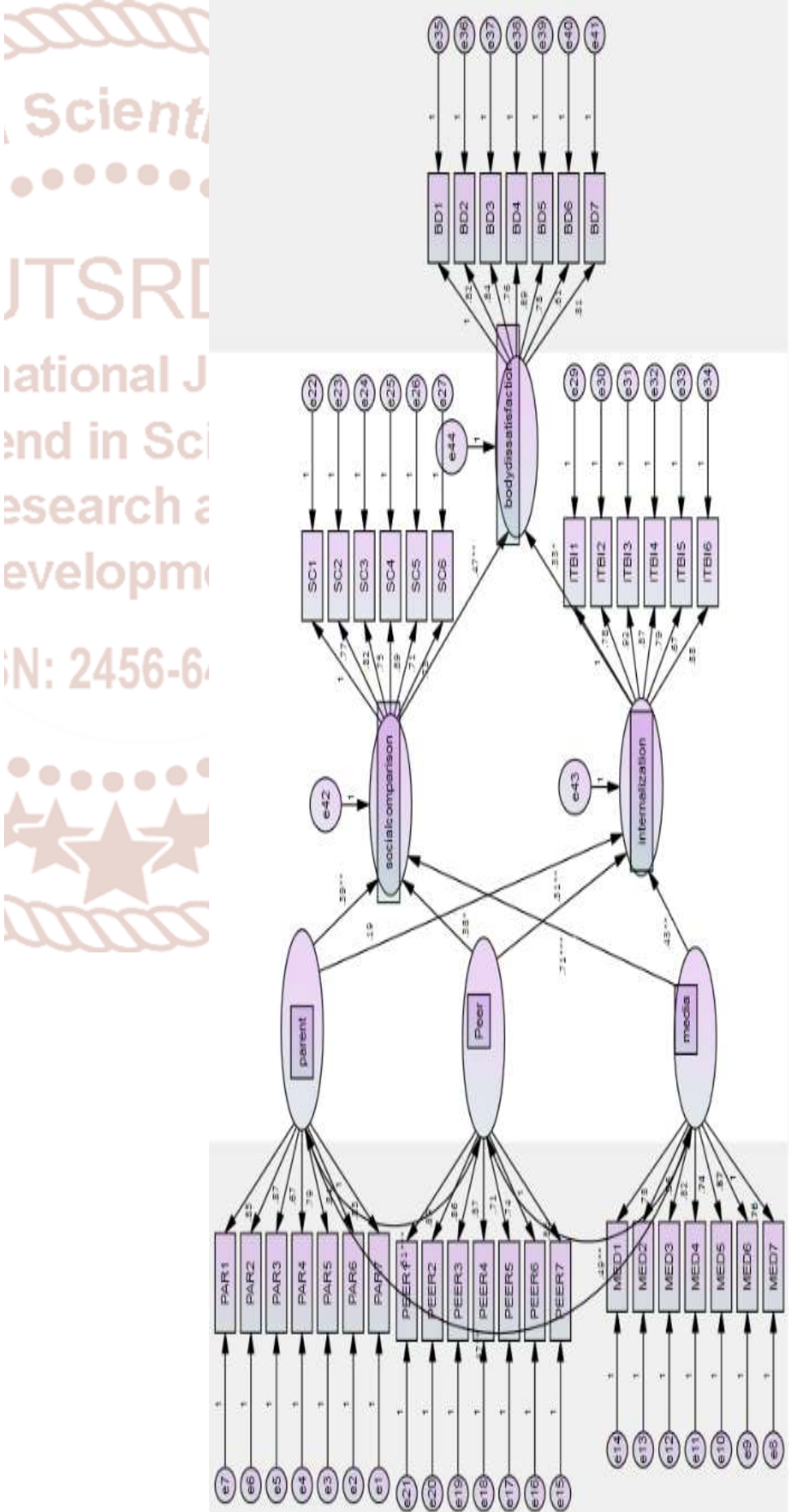




\begin{tabular}{|c|c|c|c|c|}
\hline Index & Shorthand & Criteria & $\begin{array}{l}\text { Generic } \\
\text { model }\end{array}$ & $\begin{array}{l}\text { Revised } \\
\text { model }\end{array}$ \\
\hline Chi-square & $\chi^{2}$ & Smaller the better & 2513.505 & 1031.547 \\
\hline Chi-square associated $p$ value & $\mathrm{P}$ & $\geq .05$ & 0 & 0 \\
\hline Chi-square/ Degree of freedom & $\chi^{2 / d f}$ & $\leq 2 ; \leq 3 ; \leq 4$ & 3.768 & 1.986 \\
\hline $\begin{array}{l}\text { Root mean square error of } \\
\text { Approximation }\end{array}$ & RMSEA & $\begin{array}{l}.05<\text { value } \leq .08 \\
\text { acceptable } \leq .05 ; \text { good }\end{array}$ & 0.06 & 0.041 \\
\hline RMSEA associated $p$ value & PCLOSE & $\geq .05$ & 0 & 1 \\
\hline Tucker-Lewis Index & TLI & $\begin{array}{l}.90 \leq \text { value }<.95 \\
\text { acceptable } \geq .95 ; \text { good }\end{array}$ & 0.823 & 0.933 \\
\hline Comparative Fit Index & CFI & $\begin{array}{l}.90 \leq \text { value }<.95 \\
\text { acceptable } \geq .95 ; \text { good }\end{array}$ & 0.843 & 0.956 \\
\hline $\begin{array}{l}\text { Standardized Root mean square } \\
\text { Residual }\end{array}$ & SRMR & $\begin{array}{l}.05<\text { value } \leq .08 \\
\text { acceptable } \leq .05 ; \text { good }\end{array}$ & 0.0764 & 0.0630 \\
\hline Hoelter's Critical N & Hoelter Index & $\begin{array}{l}75 \leq \text { value }<200 \\
\text { acceptable } \geq 200 ; \text { good }\end{array}$ & 162 & 267 \\
\hline
\end{tabular}

Eliminating manageable variable with inconsequential factor loading yielded substantial upgrading in the reviewed model fit compared to the nonspecific one. Goodness of Fit Statistics for both the generic and reviewed model is shown in above table:

Excluding for the chi-square allied $\mathrm{p}$ value, the goodness-of-fit actions designate a good model fit to the facts for the reviewed structural equation model. Chi-square allied $p$ value is lesser than .05 , screening that there is a metamorphosis between the conjectured covariance matrix and the detected covariance matrix.

\section{Regression Weights: (Group number 1 - Default model)}

\begin{tabular}{|l|l|l|l|l|l|l|l|}
\hline & & & Estimate & S.E. & C.R. & P & Label \\
\hline ITBI & $<--$ & Parent & .19 & .045 & 4.658 & .011 & Accepted \\
\hline ITBI & $<--$ & Peer & .390 & .053 & 5.296 & $* * *$ & Accepted \\
\hline ITBI & $<--$ & Media & .380 & .048 & 2.026 & $* * *$ & Accepted \\
\hline SC & $<--$ & Parent & .510 & .038 & 2.675 & .010 & Accepted \\
\hline SC & $<--$ & Peer & .431 & .034 & 3.836 & $* * *$ & Accepted \\
\hline SC & $<---$ & Media & .712 & .035 & 3.765 & $* * *$ & Accepted \\
\hline BD & $<---$ & ITBI & .330 & .042 & 2.248 & .010 & Accepted \\
\hline BD & $<---$ & SC & .472 & .041 & 4.867 & $* * *$ & Accepted \\
\hline
\end{tabular}

Above diagram shows the results of path analysis and regression weights. Results indicates that (parent, Peer, Media) has direct positive effect both mediating variables Internalization of thin beauty ideal and social comparison has direct positive effect $(\mathrm{H} 7$ : estimate $=.330, \mathrm{t}=4.294, \mathrm{p}<0.001)$, mediating variable internalization of beauty ideal on body dissatisfaction has direct positive impact (H8: estimate $=0.472, \mathrm{t}=2.453, \mathrm{p}<0.001$ ) mediating social comparison has direct positive effect. It has been indicated that path analysis supports all the hypotheses of the study. 


\section{CONCLUSION}

\section{Discussion:}

The projected model experienced dissimilar hypotheses around the connection among stevoked constructs parental influence, peer influence, media influence and mediating variables and outcome variable body dissatisfaction. In contemporary model progressive variables were hypothesized mediated through the procedure of social comparison and internalization of thin ideal body. With no straight pathways stimulusto the body dissatisfaction encompassed, was found to be the greatest appropriate to the data. Sketchily discourse, this suggests that the relationship amongst more distal influences was in detail interceded by social comparison and internalization of thin ideal body.

\section{Conclusion:}

In Islamic republic of Pakistan internalization of appearance ideal body and social appearance comparison emerged as significant prognosticators of body dissatisfaction and mediate the relationship of social influence and body dissatisfaction. Finding could be useful to understand the process of media pressure on females that dysfunction their body image perception and persuade them to adopt materialistic lifestyle and objectified themselves in society, although these females are in intense pressure and fighting to gain their basic rights. Findings also provide platform to develop preventive measure to stop objectification of females and help to incorporate the programs that reduce the formative pressure on females that force female to feel dissatisfied their bodies and image perception.

\section{Practical Implications:}

In 2006, exaggeratedly thin models were proscribed from a top-level fashion spectacle in Madrid, Spain because of the apparent destructive inspiration they could have on fledgling adolescents. The provincial administration whispered that phantasmagorias of skin-and-bone models would encouragement adolescents to participate in morbid practices to attain the shrill figure they exemplified. Thirty percent of the models who grabbed fragment in the aforementioned fashion show were rotated absent. This unparalleled incident in which a form of bowdlerization was overseen based on a presumed impact is just a particular illustration of the prominence in identifying the favoritisms of discernments and peculiar amongst discernments of impact and genuine encouragement.

\section{Limitations:}

The first limitation of present study is that Muslim ethnicity should be investigate with respect to the body image perception and used as a mediating variable, Secondly the self-control and internal locus of females may change the effect of social appearance comparison on body dissatisfaction was not investigated. Thirdly the body shape of female respondents was not investigating to find out that the dressing culture and appearance shaped persuade by media match with the targeted females in ordinary role, these females feel comfortable and look good on their bodies. Furthermore, the phenomena not investigate for longer period of time to measure the change in perception of females in their developmental period.

\section{Future Research:}

The consequences unveil in this research make available in cooperation theoretical and practical application. In sequence gather from the person discussion session adds shore up and wealthy aspect to numerous theories counting the third-person effect, attribution, prejudiced cheerfulness and social comparison. By allow informants to give response in their own words, a more absolute picture of the thirdperson effect dynamics was exposed. For academic circles, this study has also Open Avenue for future inquiry into the media's role in female body image. One of the first possibilities for additional inquiry would be to additional scrutinizing the overturn thirdperson effect when compare the media's influence on men and women.

\section{REFERENCES}

1. Abraham, S. L.-j. (2001). eating disorder.

2. Adlard, L. (2006). The relationship between body dissatisfaction of mothers and body dissatisfaction of their adolescent daughters.

3. Ahmar, T. (2012, June 9). www.newslinemagazine.com. Retrieved January 20, 2014,

4. From,http://www.newslinemagazine.com/2012/06 /portrayal-of-women-in-Pakistani-dramas.

5. Ainsworth, M. D. S., Blehar, M., Waters, 
6. E., \& Wall, S. (1978). Patterns of attachment. Hillsdale, NJ: Erlbaum.

7. Arshad, F. (2012, July 18). Women-ofpakistan.blogspot.com. (Enough) Retrieved January 25, 2013, from http://woman-ofpakistan.blogspot.com/2012/07/womens-

portrayal-in-media.html

8. Berg, P. K. (2007). Body dissatisfaction and body comparison with media images in males and females. Science Direct, 257-268.

9. Blowers, L. F. (2003). The relationship between sociocultural to be thin and body dissatisfaction in preadolescent girls. Eating behaviors, 4 (3), 229244.

10. Bowlby, J. (1969). Attachment and loss. Vol. 1 \& 2. New York: Basic Books.

11. Cash, T. F. (1997). The body image workbook: An 8-step program for learning to like your looks. Oakland, CA: New Harbinger Publications, Inc.

12. Cash, T. F. (2000). Multidimensional Body-Self Relations Questionnaire: MBSRQ users' manual. Norfolk, VA: Old Dominion University.

13. Cheng, H.-L. M. (2009). Parental bonds, anxiety attachment, media internalization, and body image. Journal of counseling psychology, 56 (3), 365-375.

14. Dohnt, T. (2006). Body image concerns in young girls: The role of peer and media prior / to adolescent. Journal of youth adolescent, 35 (2), 135-145.

15. Domini. N. L., Johnston, W. B., \& Koch, K. (2000). Perception of parental acceptance in women with binge eating disorder. The Journal of Psychology, 134, 23-40.

16. Durkin, S. J., Paxton, S. J., \& Sorbello, M. (2007). Dissertation Abstracts International, 66, 2816.

17. Eric Stice, K. W. (2002). Risk factor of body dissatisfaction in adolescent Girls: A longitudinal investigation. Development psychology, 38 (5), 669-678.

18. Erikson E. H. (1968). Identity, youth and crises. New York: Norton.

19. Furnham, B. (2002). Body image dissatisfaction: Gender differences in Eating attitude, SelfEsteem, and reason for exercise. The journal psychology, 581-596.
20. George, H. R. (2010). The effects of media exposure on body.

21. Gilligan C. (1982). In a different voice. Cambridge, MA: Harvard University Press.

22. Green, P. (2003). Predictors of body dissatisfaction in adult men and women. Social behavior and personality, 31 (3), 215-222.

23. Grigg, M., Bowman, J., \& Redman, S. (1996). Disordered eating and unhealthy weight Reduction practices among adolescent females. Preventive Medicine, 25, 748-756.

24. Halls, S. B. (2004, September 5). Ideal weight and medical definition of overweight .Retrieved October $\quad 15, \quad 2014, \quad$ from http://www.halls.md/ideal-weight/medical.htm

25. Heinberg, L. J., Wood, K. C., \& Thompson, J. K. (1995). Body image. In V.I. Rickert (Ed.), Adolescent

26. Jackson, L. A. (2002). Physical attractiveness: A sociocultural perspective. In T.F. Cash \& Pruzinsky (Eds.), Body image: A handbook

27. Jalees, T. (2004). Impact of social culture factors on social / comparison, internalization and body image in Karachi.

28. Joan costa-fonta, M. j.-b. (2011). Anorexia, body image and peer effects: Evidence from sample of europen women. The London school of economics and political science.

29. Kawecki, A. M. (2010). Beauty is pain: The physical, Psychological, and Emotional Impact of Female Media.

30. Kemp, L. (2007). Body dissatisfaction and self efficacy in college female social groups.

31. Kennett, H. S. (2012). Sexual resourcefulness and the impact of family, Sex education, media and peers. Sex education, 12, 351-368.

32. Kenny, M. E. (1987). The extent and function of parental attachment among first-year college students. Journal of Youth and Adolescence, 16, 17-29.

33. L.Wagaman, A. (2011). The Media's influence on college females' body satisfaction. Wastren Carolina University Cullowhee, North Carolina.

34. Li-Jung Chen, K. R.-W. (2010). correlate of body dissatisfaction among Taiwanese adolescents. 
Asia pacific journal of clinical nutricining, 172179.

35. Miller J. B. (1976). Towards a new psychology of women. Boston: Beacon Press.

36. Miller, E. a. (2005). Media consumption, body image and thin ideals in New Zealand men and women. New Zealand journal of psychology, 34 (3), 189-195.

37. Nolen-Hoeksema, S. (1990). Sex differences in depression. Stanford, CA: Stanford University Press.

38. Offer, D., Ostrov, E. \& Howard, K. I. (1982). Family perception of adolescent self image.

Journal of Youth and Adolescence, 11, 281-291.

39. Paterson, J., Pryor, J., \& Field, J. (1995). Adolescent attachment to parents and friends in relation to aspects of self-esteem. Journal of Youth and Adolescence, 24, 365-376.

40. Riaz, K. (2010, December Szabithinkers.blogsspot.com. Retrieved from

5). http://szabistthinkers.blogspot.com/2010/12/portr ayal-of-women-in-ourpakistani.html

41. Shah war, D. (2013). A Study of Audience Perception about the Portrayal of Women in Advertisement of Pakistani Electronic Media. Journal of global and science, 1 (2).

42. Sue-Yee Tan, W.-P. Y. (2012). The relationship between body dissatisfaction and eating disorder among exercisers. SEGI Review, 5 (1).

43. Sugar M., (1993). Female adolescent development. New York: Brunner Mazel.

44. Tergouw, M. v. (2012). Peer influence on the body satisfaction of adolescent girls: Where do we go from here? Social cosmos.
45. Thompson, J.K. (1991). Body Shape Preferences: Effects of Instructional Protocol and Level of Eating Disturbance. International Journal of Eating Disorders, 10, 193-198.

46. Tylka TL, A. M. (2012). Support for an expanded tripartite influence model with gay men. Body image, 57-67.

47. Usmiani S.\& Daniluk J. (1997). Mothers and their adolescent daughters: Relationship between selfesteem, gender role identity, and body image. Journal of Youth and Adolescence, 26, 45-62.

48. Vandereycken, W., Kog, E., \& Vanderlinden, J. (1989). The family approach to eating disorders: Assessment and treatment of anorexia and bulimia. New York: PMA.

49. Wagaman, A. L. (2011). The media's influence on college females' body satisfaction.

50. Wykes, M. \& Gunter, B. (2005). The Media and Body Image. London: SAGE Publications Ltd.

51. Yuko Yamamiya, e. s. (2008). The tripartite influence model of body image and eating disorder: A replication with a Japanese sample. International journal of eating disorder, 41 (1), 88-91.

52. Zain-ul-abiden, A. 1. (2011). Impact of media on development of eating disorder in young females of Pakistan. International journal of psychological studies, 122-147.

53. Zaman, M. (2009, October 9). www.ips.org.pk. (SGGI working group) Retrieved January 19, 2014, from http://www.ips.org.pk/archives-ofwhats-new/163-workinggroupwomen/1630feminism-and-media.html

54. Zia, A. (2007). Media and gender: Pakistani perceptive. 